\title{
4 Educating for Intellectual Humility
}

\author{
Ian James Kidd
}

\section{INTRODUCTION}

The claim that education ought to be directed to the cultivation of virtues enjoys both venerable precedent and growing contemporary popularity. Many contemporary philosophical virtue theorists have begun to restore the sense of an intimacy between virtue, character, and "the good life," and, in turn, philosophers of education explore the ways that educational practice could contribute to the cultivation of virtuous character. Certainly many philosophers and educationalists will agree with Ben Kotzee that it is "obvious" that education ought to "form good intellectual character" (2014, p. 8). I am sympathetic to this claim, but also sensitive to the worries of those skeptics who ask about the practical, pedagogical, and philosophical issues it raises. Central among these concerns of such skeptics is what sorts of virtues should be educated for, a concern amplified by the fact that virtue ethicists and epistemologists have identified and offered complex accounts of so many candidate virtues.

My purpose in this chapter is to contribute to the revival of aretaic conceptions of education, but in a way sensitive to those skeptics' concerns. Expressly, I offer an account of the specific virtue of intellectual humility, then show its integral role in a range of familiar educational practices and concerns, and finally describe how certain entrenched educational attitudes and conceptions marginalize or militate against the cultivation and exercise of this virtue. The chapter ends by suggesting that educational attitudes, practices, and systems can be appraised according to the extent to which they are conducive to the cultivation and exercise of virtues and vices: or more simply, whether they are edifying or corrupting.

As a final caveat before beginning, I'll stop prefixing terms such as "confidence" and "humility" with the term "intellectual," partly for reasons of brevity, and partly because repetition dulls the mind.

\section{CONFIDENCE AND HUMILITY}

My claim is that humility is a virtue for the management of confidence. At first glance, though, this might sound odd. Typically one finds that these 
two qualities are contrasted with one another. A confident person operates with a sense of assumptive capability, unlike their humble peer who demurs, hesitates, and pulls back. Some philosophers have codified this contrast by either describing confidence and humility as opposing virtues-the former pulling us up, the latter pulling us down-or simply by denying humility its status as a virtue. Although such contrastive views of confidence and humility are well established in everyday thought and talk, we risk prejudging their relationship if we automatically accept them. As Socrates taught us, there is, very often, no good reason to defer uncritically to people's typically implicit, everyday grasp of complex concepts such as virtues.

The relationship of confidence and humility is better understood if we distinguish between a person's capacities (cognitive, physical, social) and their associated confidence in them. Such a distinction will often be hard to draw, but it is genuine nonetheless for the reason that it is one thing for a person to possess certain capacities, but quite another for them to enjoy corresponding confidence in them (and, in fact, the image of a perfectly capable but severely unconfident person should be familiar to anyone with a modicum of empathy). The relevant forms of confidence will vary but might include confidence that one possesses those capabilities, that they are stable and reliable, that one can access and control them as one desires, and so on. These forms of intellectual confidence will often be implicit and so difficult to recognize but will, of course, become more visible when they are lost or lacking; for example, if a person enjoys a high degree of confidence except when in certain situations or among certain persons-before a public audience, say, or around bullying colleagues.

Intellectual confidence is therefore complex, contingent, and multi-layered, but also essential to the proper recognition and exercise of one's capacities. The scope and strength of one's confidence shapes a person's sense of the activities and projects they could plausibly undertake, the situations in and persons with whom they could live and work, and their wider sense of their prospects and ambitions. Indeed, the crucial role of confidence is negatively illustrated by the fact that an effective way to oppress other persons is to erode their confidence, for instance, by subjecting them to strategies of derogation-such as mockery, ridicule, and "gaslighting." It is for these reasons that Adrian Moore rightly describes confidence as "a good, without which there would not be any such thing as living a life" (quoted in Williams, 2006a, p. xviii-xix).

The claim that confidence is a good is reflected in the prestige it enjoys among philosophers of education. The British philosopher of education, R.S. Peters, argued that through education a student ought to gradually "earn the right to confidence in [their] belief," by acquiring and mastering the "capacity to make a reasonable case" for what they believe (2009, p. 90). The teacher should, adds Peters, foster their student's "confidence in his own powers," thereby developing the "self-confidence . . . necessary for being a chooser" (1998, p. 20). If so, education and confidence clearly pull together, for it is precisely through educational practice and experience 


\section{Ian James Kidd}

that a student can develop the capacities, habits, and dispositions that are required for confident intellectual activity-those of carefully forming, critically evaluating, and reasonably expressing beliefs and convictions to other equally educated peers.

The double achievement of both a "capacity" and a "right" to belief marks an important step from confidence to humility. Bernard Williams distinguishes between two types of confidence. The first is "reasonable confidence," grounded in reflection and deliberation, including intellectually and ethically mature engagement with a community of peers. The second is the "confidence of bigotry," rooted in assumption, bias, and prejudice and sustained by the derogation or exclusion of alternative perspectives (1995, p. 203). Ideally, education should challenge bigoted confidence by affording acquaintance with facts, ideas, and degrees of knowledge and understanding that expose the bigoted nature of that confidence. Williams later adds that the fact that reasonable confidence is achieved through educative endeavor with others, including peers and teachers, indicates that confidence is "a social state ... related to discussion, theorizing, and reflection” (2006b, p. 170).

Confidence emerges as a complexly social and intellectual quality. It is cultivated and expressed through shared social practices in the context of activities and projects that have an inescapably intellectual dimension-for example, arguing, believing, and convincing. This is why the dynamics of confidence affect so profoundly a person's capacity to navigate and flourish within the social world, especially given that intellectual confidence structures our capacity for rational agency. Moreover, such confidence can clearly be excessive or deficient - one can be arrogant or meek - and these constitute misestimates of a quality upon which personal agency and social life fundamentally depend. This being so, it is crucial that persons can manage or regulate their intellectual confidence, and this is where I see a role for virtues.

There are doubtless many virtues that contribute to the regulation of intellectual confidence for at least two reasons. The first is that the virtues tend not to be rigidly sealed off from one another. At least within "real-world" practical and social contexts, the activity of one virtue will tend to call other virtues into play, for instance, if being just by standing up for an unfairly oppressed group demands courage. The second is that the regulation of intellectual confidence necessarily involves interpersonal interactions and relationships, not least with peers and teachers, and this straightaway makes a role for virtues such as trust, respect, and empathy.

Still, the fact that many virtues play a role does not exclude the possibility that certain virtues play a special role, and I suggest that humility has a special role in the management of confidence. Like Ward E. Jones, I see a close connection between confidence and humility, but where he sees an "intimate relation," I see a deeper identity between them (2012, p. 698). A state of intellectual humility is identical to well-regulated or calibrated confidence that is integral to a broader structure of regulative activities that is constitutive of a good and flourishing life. 
Concisely, then, humility is a virtue for the management of confidence. Although there are many possible ways to cash out that claim, let me focus upon what I take to be the most important. This is the idea that confidence has levels at which it operates and that intellectual humility requires a special sensitivity to these levels. The first level is agential confidence: the confidence a person invests in their cognitive capacities and experiences, skills and training, and perhaps their general "self-trust" in their status and ability as an intellectual agent, able to pursue and attain truths about the world, say (cf. Zagzebski, 2012). But agents, of course, do not act alone; they must typically engage with and rely upon others, and this points to the next level.

The second level is collective confidence: the confidence invested in others, including peers, teachers, and the social communities with which one engages. These might be fairly informal spontaneous collectives-perhaps the delegates to a conference or more formalized institutional or professional collectives, such as the faculty of an academic department or the community of philosophers of science. Collective confidence might take the form of a confidence in the competence and goodwill of colleagues, or in the integrity of one's institution, or in the civility, fair-mindedness, or professionalism of one's fellow inquirers. But both agents and collectives must also share a further, deeper confidence, and this points to the third and final level.

This is the level of deep confidence: the confidence invested explicitly, or perhaps more typically implicitly, in the deeper social, intellectual, and historical foundations upon which individual and collective activities and projects rest. Such deep confidence might take the form of a robust sense of possibility of making intellectual progress within a given agenda of inquiry, or a deep confidence in the fundamental solubility of even the most difficult problems that lie in the path of inquiry. Alternatively, deep confidence could be invested in the richness of the intellectual heritage that shapes the agenda of inquiry and specifies relevant problems_of Michael Oakeshott's faith in "standards of worth" flowing from the "inheritance of human achievement" of which the teacher is the "living custodian" (2004, p. 379).

Clearly, deep confidence can be invested in many different things-God's ordained order, scientific reason, Spirit's rational progress-and helps to "ground" the intellectual and cultural activities of a given culture. Many decisive episodes in the history of philosophy could, perhaps, be interpreted in terms of radical shifts, by loss or by gain, of a culture's deep confidence. The Canadian philosopher Charles Taylor, for instance, has characterized the emergence of modern doctrines of secular humanism as a loss of confidence in "God's saving action," coupled with a newfound deep confidence in human "powers of moral ordering," partly through ambitious projects of educative and social reform (2007, pp. 27, 83, 121).

These three levels of intellectual confidence are neither sharply demarcated from one another nor rigidly stable. Indeed, these levels interact and change, especially since a loss or gain of confidence at one level can have effects upon the others. If a male philosopher becomes cognizant of the 


\section{Ian James Kidd}

phenomenon of implicit gender bias, then his confidence might be negatively affected-for instance, by recognizing the untenability of his prior confidence in the impartiality and gender-neutrality of himself, his peers and colleagues, and the philosophical tradition (see, e.g., Jenkins and Hutchison, 2012, and Saul, 2013). It is also true that confidence can be restored, even if the loss is likely to be quicker than the restoration, and even though the restored confidence will likely be more fragile.

The contingency and fragility of confidence is an important aspect of humility. It explains why managing confidence is difficult, important, and, hence, why there is real work for the virtue of humility to do. An intellectually humble person is alert to the contingency and fragility of their confidence and so acknowledges the need for its active management or regulation. A main way to do this is to develop and employ robust practices of confidence-calibration. By that term, I refer to cognitive and social practices whose purpose is to gauge agential, collective, and deep confidence, and these can take many different forms: for instance, basic fact-checking, debate and argumentation, psychological studies, historical inquiry, and, of course, philosophical practice.

In each case, and in different ways, a person is identifying and testing the grounds for their confidence; indeed, etymologically, the origin of the term for "humility" in Greek, Latin, and Sanskrit is the term for "earth" or "ground," and the history of Western epistemology evinces a series of metaphors of "grounds" and "foundations" for belief or certainty. Moreover, prevalent rhetorics of humility often play on this association-as we talk of "getting a good grounding" in a new subject, for instance.

Such practices of confidence-calibration can take many forms and are highly shaped by professional and social context. I might seek formal and systematic calibration of my confidence by submitting publications for peer review or by seeking structured academic training with a supportive supervisor. Or I might seek more informal spontaneous calibration, perhaps by asking for feedback after giving a talk or by running my ideas past the barista who makes me coffee every day. Many of the norms and practices of the social culture of modern academia can be interpreted in terms of practices for confidence-calibration-formal or informal, spontaneous or systematic-and they all reflect the fact that, individually, human beings tend to be rather poor at intellectual self-improvement, such that externally structured intersubjective practices of correction are our best prospects (see, e.g., Ahlstrom-Vij, 2013).

To conclude this section, our intellectual activities, and therefore our social lives, depend crucially upon our being able to exercise our intellectual capacities, and this in turn requires that we can invest them with the appropriate degrees of confidence. Unfortunately, confidence is complex, contingent, and highly shaped by situational and intersubjective factors, and it operates at the psychological, social, historical, and even metaphysical levels. I think that humility can begin with two insights: The first is 
the complex, conditional, and contingent status of our confidence, and the second is the need to embrace attitudes and practices that enable its management. These insights also point to the truth in Ludwig Wittgenstein's curt warning that it is "terribly hard work" for a person to try seriously to "dismantle ... the edifice of [their] pride" (1980, p. 26).

In the following two sections, I further develop these remarks by offering a more systematic account of the virtue of intellectual humility.

\section{CONFIDENCE CONDITIONS}

The virtue of humility consists of two pairs of components. First, the humble person is disposed to recognize the relevant confidence conditions for a given assertion, belief, or conviction, and the extent of their fulfillment of them. Second, they then act on this recognition by using it to regulate their intellectual conduct accordingly. In this section, I focus upon the "recognition-disposition" and the idea of confidence conditions. Importantly, these two dispositions only optimally function through mutual interaction, and genuine humility, therefore, requires them both.

The starting point for this disposition is the idea that assertions, beliefs, and convictions always depend upon certain conditions that ought to be fulfilled if a given agent can legitimately assert, believe, or act with confidence. The conditions underlying a given intellectual act will often be fairly obvious, because an assertion or belief will typically be about a given topic-such as Derrida or poultry farming or Etruscan pottery-and so point us in certain directions. Unfortunately, there are many other cases where the underlying conditions are more difficult to identify, and this is another reason why humility often requires real cognitive work.

There are three broad types of confidence conditions that parallel the levels of confidence identified in the last section. The first are agential conditions: These reflect the fact that our intellectual capacities are conditioned by physical, cognitive, and experiential factors-sensory faculties, cognitive abilities, first-hand experiences, practical and professional training, and so on. An agent might justify their confidence by pointing out what they know or have experienced, which explains why a standard response to a person who makes wild or unusual claims is to query their grounds for confidence"What makes you think that?" "Have you even been there?"-and also why formalized systems of accreditation, such as CVs, are so useful.

The second are collective conditions: the confidences that are justified by appeal to the collectives with whom we live, work, and think. I might be confident in my claims about the virtue of humility because I trust my constructively critical peers and can draw upon the richness and support of the community of virtue epistemologists. An agent can justify their confidence collectively by debating with colleagues, presenting work to peers, and finding encouragement and direction from fellow inquirers-and, again, we test 


\section{Ian James Kidd}

our judgments of people's confidence by asking if they know this person, have read that book, or have worked with this group, and so on.

The third and final types are deep confidence conditions. The possibility and intelligibility of our intellectual activities and ambitions inevitably relies upon certain background conditions. Many theorists have explored different possible objects of deep confidence- “paradigms," Lebenswelt, projects of inquiry-and other historical, transcendental, and phenomenological structures. Such conditions ground deep confidence in, for instance, the possibility of rational inquiry into the nature of reality, and often a community might only become aware of these deep conditions when its confidence is shaken or lost. Oakeshott, for instance, found in the many "voices" that made up the "conversation of humankind" a basis for deep confidence in the rationality and conviviality of our species $(2004$, ch. 8$)$. But perhaps he would have lost some of that confidence had he recognized that the range of those voices was less plural, and more parochial, than he appreciated.

An intellectually humble person is disposed to recognize the confidence conditions that underlie assertions, beliefs, and convictions, whether their own or those of others. In this chapter, though, I focus only upon "self-directed" humility. Such recognition has two aspects: the first is recognition of the conditions that are relevant to a given assertion (and so on), and the second is recognition of the extent to which they fulfill those conditions. One might say the humble recognize what conditions they need to fulfill and whether they do or could fulfill them, and, of course, such recognition ought to be consistently applied and reliably achieved. It is an act of humility to recognize such underlying conditions and the extent, if any, to which one fulfills them. It is at this point that other virtues would play a cooperative role in enabling humility. For instance, it surely takes courage, discipline, and trust to engage in the self-directed critical practice that Wittgenstein called "dismantling the edifice of pride."

Intellectual humility is clearly a difficult virtue that demands real cognitive work. The humble person has to be alert to their assertions, beliefs, and convictions, to identify and track the changing confidence conditions that underlie them, and to do all of this alongside their everyday cognitive work. Certainly humility cannot take the form of one-off episodic intellectual housekeeping, even if it will periodically require fairly robust self-appraisal of a sort common in Western antiquity and then revived during the early modern period in the form of "meditations," "regimens of the mind," and other signs of a "shift toward ... intellectual virtue" in the context of "distempers of the whole mind and . . . cultivating regimens" (Corneau, 2011, pp. 4, 7). An essential component of these active practices of confidence-calibration will be education.

Specifically, I suggest that there are three ways that education can contribute to the cultivation of a capacity to recognize confidence conditions. First, education can inform a person about the fact and complexity of confidence conditions, most obviously by providing information about the range of things about which one could offer assertions and form beliefs. A student 
must have an initial sense of the possible objects of assertion, belief, and conviction if she is to embark upon the task of identifying the confidence conditions that underlie them. Second, education can inspire a respect for confidence conditions and the need to fulfill them so that they come to see the truth in Peters's call for them to "earn the right" to confident belief and in Williams's distinction between reasonable confidence and the confidence of bigotry. A student might gradually come to feel delight at providing grounds for her assertions and beliefs and find that she interdicts her peers who make confident assertions without fulfilling the necessary conditions. And third, education can induct a student into practices of confidence-calibration-of arguing, debating, and so on —and, in fact, many familiar educational practices already have this purpose (such as dialectical exchange, receiving and responding to feedback, and so on).

Education can contribute to the cultivation of intellectual humility by informing, inspiring, and inducting students into the dispositions and capacities that are required if they are to recognize the relevance and fulfillment of the confidence conditions that underlie their assertions, beliefs, and convictions. Such educative experiences will also hopefully cultivate other virtues, including the ones that regulate interpersonal exchanges-such as trust and open-mindedness-especially given that learning to recognize confidence conditions requires sustained engagement with peers who are almost certain to offer challenges to, and criticisms of, our confidence.

Though the recognition-disposition is necessary to humility, it is, by itself, insufficient for a full account of that virtue for the reason that it does not distinguish humility from several of its associated vices. A person might, for instance, be perfectly good at recognizing confidence conditions and the extent to which they fulfill them, but also reliably fail to actually act on the basis of that recognition. For instance, an arrogant person could plausibly be described as someone who recognizes that they do not fulfill the confidence conditions for a certain claim, but ignores this and makes strong assertions anyway-one might say, they know better, but don't act on it. Humility is, therefore, too narrowly construed if it is confined to the recognition of the fulfillment of relevant confidence conditions-what is also needed is a further disposition to act upon that recognition by using it to guide or direct how one conducts oneself intellectually.

In the next section, I explain the second pair of components that make up the virtue of humility: the disposition to regulate one's intellectual conduct.

\section{INTELLECTUAL CONDUCT}

I take the idea of intellectual conduct to be crucial to our understanding of intellectual virtue and especially of its relation to education. By that term, I refer to a person's manner of conducting, directing, and managing their intellectual activities, including how they form beliefs, articulate claims, and especially how they engage with other persons, ideas, and traditions. 


\section{Ian James Kidd}

Intellectual conduct includes a range of affective, behavioral, and cognitive dispositions and manifests in posture, tone, and bodily and verbal language and might also be understood in terms of style or demeanor. The way in which a person conducts themselves intellectually will be expressed in how they phrase their claims, voice their concerns, state their worries, present their criticisms, hold to their convictions in the face of challenge, and so on.

One might legitimately ask how intellectual conduct is distinguished from social conduct, given their obvious proximity to one another-of how, for instance, one might distinguish what Locke called "conduct of the understanding" from a broader sense of personal and social conduct. The answer is that the expectation of a sharp distinction between intellectual and social conduct ought to be rejected, given the centrality of our intellectual activities and commitments in our practical and social activities and engagements. A main reason why ethics and epistemology are so deeply interpenetrated is that everything we do in the social world involves epistemic concepts and concerns-knowledge, doubt, certainty, and so on-a fact recognized by the Pyrrhonian and early modern skeptics. My sympathies clearly lie with "regulative" or "responsibilist" conceptions of the nature of epistemology and of its relation to ethics (cf. Kidd, 2012).

Central to my general view of the virtuous inquirer is that they are disposed to regulate their intellectual conduct, and this is something that I suspect is therefore a component of all of the intellectual virtues. Each intellectual virtue has its shared and specific functions, which can be "mapped" in various ways, but each is a component of the more general regulative activity of aspiring to, if not achieving, good intellectual conduct, intellectual virtuousness, or whatever one wishes to call it (see, e.g., Roberts and Wood 2007, part II).

Clearly there are many different forms of intellectual conduct, and perceptions and preferences vary between individuals and across history and culture. Many classic texts in the history of philosophy could be read as descriptions of different forms of intellectual conduct-of the virtues and conduct that characterize the Stoic sage, a Confucian "consummate person," and other exemplars of virtue. A very rich example is the Analects of Confucius-an edited collection of sayings, observations, and episodes, rather than a book written by the Master-which offer rich descriptions of the attitudes, speech, and behavior of the virtuous aspirant (see, e.g., Olberding, 2011). Central among these virtues is what I have called intellectual humility: to have an active awareness of "abilities that one does not possess," to "love" and "stand in awe" of the "teachings of the sages" and "antiquity," and to always "find a teacher [and] emulate them" is humble recognition of collective and deep confidence $(2003$, $\mathbb{S} \$ 85,7.20,16.8,7.22$; cf. Rushing, 2013). Such texts describe the person who is well-conductedethically, socially, intellectually-and who exemplifies a virtuous life.

For present purposes, I focus only upon the specific aspects of good conduct that reflect intellectual humility, the core of which is reflectively 
responding to their changing fulfillment of the confidence conditions relevant to their assertions, beliefs, and convictions. A crucial difference between the humble person and their arrogant or meek peers is that they can effectively regulate their conduct and, so, avoid the excessive confidence of the arrogant and the deficient confidence of the meek. To be intellectually well-conducted is, therefore, in part to have well-managed confidence, and this is the particular contribution of the virtue of intellectual humility, alongside other virtues relevant to confidence-calibration and to other aspects of intellectual life.

Such conduct-regulation can take three related forms, distinguished by the aspect of our intellectual conduct that is being regulated. The first is appraisal-regulation: specifically, an agent's self-appraisal of the scope and strength of their intellectual capacities, and it will most obliviously take the form of judicious up- or downgrading of their confidence. The second is attitude-regulation: Much of our intellectual life is structured by attitudes, either positively or negatively valenced, toward a range of objects, including other agents and certain collectives, but also ideas, styles of argument, types of evidence, whole disciplines, entire intellectual traditions, and so on. Such attitudes ought to be regulated, because they constitute our preemptive and often unreflective sense of the space of intellectual possibilities-the structures of intelligibility, salience, and cogency that shape our intellectual life, including what one welcomes or resists, derogates or demeans, praises or promotes, and so on. Such attitudes are often explicitly stated-a distinguished American philosopher once had a poster reading, "Just say NO to the history of philosophy"-or they might be implicit in certain remarks, jokes, or facial expressions. The regulation of agential and collective intellectual attitudes is an essential aspect of good intellectual conduct, especially because our capacity to cultivate certain virtues is crucially premised upon our engaging with persons, ideas, and approaches very different from our own. It is, after all, a poor sort of tolerance that only speaks to its friends.

The third form of conduct-regulation is ambition-regulation. Typically, individuals will organize and direct their inquiries according to a certain set of ambitions - to write the definitive monograph on a particular person, say, or to restore the reputation of a neglected thinker. Many features of modern academic training can be understood as formalized structures for ambition-regulation, including doctoral supervision that ought to guide a student through the processes of identifying, researching, defining, and completing a focused and achievable project of work. Ambition-regulation can take different forms. It might involve adjusting an ambition, perhaps by focusing upon a single text by an author rather than an entire corpus, or alternatively abandoning an ambition newly recognized to be beyond one's abilities, or finally it could involve adopting new ambitions-for instance, if one realizes, to one's surprise and delight, that one in fact fulfills the relevant confidence conditions to a far higher degree than one suspected. The fact that a person could adopt a particular ambition does not automatically 


\section{4}

\section{Ian James Kidd}

entail that they should therefore adopt it, because the choice of which ambitions to pursue is affected by a range of other considerations-the humble person, therefore, has an acute sense of the ambitions that are legitimately available to them given the confidence conditions they fulfill. Acts of humility might involve adjusting, abandoning, or adopting ambitions and are not confined to abandoning or weakening ambitions - that is a negative sense of humility that I want to resist. Humility can, at least on my view, amplify, as well as attenuate, one's ambitions. Although this may seem counterintuitive, there is—to repeat an earlier point—no good reason to defer uncritically to everyday usage, especially if good reasons are given for doing so.

These three forms of conduct-regulation should be understood as integrated aspects of a single global regulative endeavor-that of conducting oneself well intellectually — rather than as isolated aspects of a more diffuse activity. Many virtues are required for the attainment of good conduct, of course, but, to repeat another caveat, I am focusing upon humility. Indeed, since a person's appraisal, attitudes, and ambitions are united in her intellectual life, one should expect such "integration," especially given that, for instance, a change in one's self-appraisal will typically affect one's attitudes toward others and one's ambitions. A person who suddenly enjoys a newfound sense of agential confidence might become more assertive around others and take on a newly expanded set of bold ambitions - though, of course, they ought to take care not to lapse into arrogance or dogmatism.

The intellectually well-conducted person should therefore evince a certain integrity, unity, and perhaps beauty. Consider Wittgenstein's uncharacteristically warm praise of Søren Kierkegaard as a "profound thinker," and, in fact, "a saint." Although the meaning of this remark is unclear, it plausibly reflects Wittgenstein's conviction that a "profound thinker" is not simply a person with profound thoughts-for any wicked devil could have those-but, rather, that a profound thinker is a person whose life "expresses" or is "emblematic of . . . these thoughts" (Schönbaumsfeld, 2007, p. 18f). To succeed in making one's life an "emblem" of one's thoughts through disciplined conduct requires and expresses virtues-carefulness, say, or truthfulness - and so can be beautiful for that reason (cf. Cooper, 2008a).

Such beautiful conduct might be grounded in the aspiration to good conduct as well as the achievement of it, especially since accepting that one still falls short, while still striving, can express humility, tenacity, and other virtues. So whether by aspiration or achievement, a well-conducted person approves of Pascal's self-directed advice to "seek my ... dignity" in the "ordering of my thought," and live according to the principle that "to think

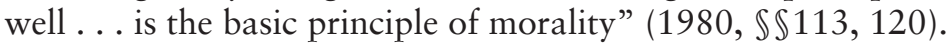

Good intellectual conduct is best illustrated practically by appeal to exemplars—such as sages, teachers, or enlightened persons (cf. Zagzebski, 2010). An exemplar might be an especially inspiring spiritual leader or a great intellectual hero from history whom one admires and wishes to emulate. Such figures can be exemplars both of the attainment of good conduct 
or, more modestly, of the aspiration to be well-conducted, and so, in this latter sense, an exemplar need not be a "saintly" figure such as Kierkegaard evidently was for Wittgenstein.

Initially, though, these exemplars might include one's teachers-perhaps a wise tutor or a charismatic lecturer. Locke advised that tutors ought to "fashion the Carriage" and "form the Mind" of their pupils by exemplifying "good Habits and Principles of Vertue" that gradually induce in them "a love and imitation of what is Excellent" (1996, \$94). Such exemplary instruction requires a sustained and attentive personal and pedagogic relationship, structured by an at least implicit appreciation of the exemplary nature of the teaching and within which exemplary conduct can be demonstrated by the tutor and discerned by the pupil (see, e.g., Yolton, 1998, and Wanderer, 2013).

Education can contribute to the cultivation of good intellectual conduct in several ways, but I will discuss just three. The first is that education can inform students about good and bad forms of intellectual conduct, explaining what it is, what makes it so, and so on. A tutor might, for instance, correct the aggressive attitudes of a tutee, or a doctoral supervisor might seek to soften a supervisee's tendency to be uncharitable toward their "rivals." The second is to inspire students to pursue and take pleasure in good intellectual conduct, evident in Confucius's efforts to teach students to appreciate the "harmonious ease" of good conduct as "beautiful," and so something to love and emulate $(2003, \mathbb{S} 1.12)$. This can be as easy as praising a student for their fair-mindedness or humility, or, of course, rebuking them for arrogance or unfairness.

The third way is that education can induct students into robust practices for the regulation of their appraisal, attitudes, and ambitions, for instance by offering them what John Dewey called a "never-ending play" of "conscious correction and instruction" within physical and social environments suitably "framed" for the shaping of "mental and moral disposition" (2012, pp. 17, 19).

The process of education can, therefore, afford structured opportunities for the cultivation and exercise of a student's disposition to regulate their intellectual conduct-of what it is, why it is good, and why it ought to be loved-by both theoretical instruction and practical demonstration. Such good conduct requires many dispositions and capacities, of course, including a capacity to recognize the relevance and fulfillment of confidence conditions - for I cannot properly regulate my conduct if I cannot gauge my confidence, not least because, in that case, I am ignorant about facts about my capacities and character that are essential to good conduct.

Over the last few sections, I have offered an account of the virtue of intellectual humility and indicated how it can be cultivated through education. My aim was not to offer a systematic account, but rather to secure the claim that it is a virtue. Still, it will be useful to briefly consider some predictable objections-for humility, qua virtue, has a bad reputation 


\section{Ian James Kidd}

among philosophers. Typically, the objections are, in quick succession, that humility requires ignorance of one's abilities and achievements, encourages a self-abnegating stance of imposed servility, and requires paradoxical self-attribution to oneself of a quality defined in terms of the disapprobation of personal praise or merit (see, e.g., Driver, 1989, and Grenberg, 2005, part 1). Such objections are typically directed at the particular conceptions of humility that flowed from the Christian tradition in the West, rather than to humility tout court. Further east, especially in Confucian philosophy, there are alternative conceptions of humility that are less vulnerable to this set of objections, thereby softening their force (see, e.g., Pardue, 2013, and Rushing, 2013).

More generally, it should be clear that the intellectually humble person I have described is defined precisely in terms of their knowledge and understanding - for instance, of a range of confidence conditions-and their having an active and acute sense of the scope and strength of their intellectual capacities. Humility, then, requires neither ignorance nor self-abasement and there is no obvious paradox in the claim that a person can cultivate a capacity to identify facts about themselves through personal and collective effort. Indeed, that is surely a primary purpose of education, a fact recognized by Locke, Peters, Oakeshott, and others.

There are, however, a set of more imposing obstacles to humility in the context of education, and they are the topic of the final section.

\section{EDUCATION, CORRUPTION, AND EDIFICATION}

Critical reflection on the state of prevailing moral and social culture is an integral feature of the philosophical enterprise, evident in the earliest and greatest figures of the Greek and Chinese traditions, including Socrates's castigation of the Sophists and Confucius's calls for revival of the "rites." Such critiques typically included commentary on contemporary educational practices and conceptions coupled to proposals for the establishment of dedicated schools and educative communities. The Garden of Epicurus, for instance, was an "academy" to cultivate the "ethical teachings of the school" by placing students within an environment in which they could become "accustomed to [the] virtues" (Rist, 1972, pp. 12, 162).

In this section, I argue that several contemporary educational attitudes and conceptions marginalize or militate against the cultivation of intellectual humility (and likely other virtues, too, though that further claim is not my concern here). This is a preparatory survey pending future investigation, and it is inspired by other "aretaic" criticisms of contemporary attitudes and conceptions (see, e.g., Battaly, 2013, and Cooper, 2008b). Though these attitudes and conceptions are diverse, their effect, both individually and collectively, is a triple erosion: first, of education as an arena for the cultivation of virtue; second, of the ideal of educators as exemplars; and third, of the 
enterprise of education as enabling-in Jason Baehr's (2013, p. 253) helpful phrase-a "fundamental orientation" toward intellectual goods. Although my discussion reflects a specific concern with humility and the management of confidence, it aligns with a set of wider concerns raised by other critics of modern education. Let me focus upon four aspects of modern education that I judge to militate against or marginalize humility as calibrated confidence.

The first are performative conceptions of education that prioritize standardized examination for quantifiable qualities, such as grades and module pass rates, often to the exclusion of all else. Performativism marginalizes teaching for virtues in general, because it imposes, incentivizes, and entrenches a myopic focus upon cognitive qualities and achievements with obvious measurable performative criteria, in several ways. For a start, humility is, like many virtues, difficult to quantify or "measure," something Aristotle recognized when he remarked upon ethics being an "inexact science" (see further Kotzee, this volume). This being so, virtues like humility tend not to feature in the standardized lists of performative criteria for students to pursue and educators to impart. Next, within performative education, humility is only likely to be acknowledged insofar as it contributes demonstrably to improved performance. This means that humility is valued only contingently and instrumentally, rather than as an independently valuable virtue and a component of good intellectual conduct. Finally, the invariably standardized character of performative education precludes the formation of the rich and personalized pedagogic relationships that the cultivation of virtues, especially via exemplary demonstration, properly requires (see Markie, 2008). Performativism is, then, hostile to educating for virtues in general, including humility.

The second are instrumentalist conceptions of education that direct curricular content and pedagogic practice toward the training of students with the skills and knowledge deemed necessary to national economic interests (what Oakeshott disparagingly dubbed the "service industry" conception of education). Instrumentalism also marginalizes virtues, but incorporates a particular hostility to humility, for at least three reasons. One, educative focus is placed on information, skills, knowledge, and dogmatic pedagogy rather than cultivated excellences of character-that is, virtues-and students are rewarded for their ability to rapidly and reliably absorb those cognitive skills, rather than their commitment to the improvement of their characters-they internalize an ambition to become cognitive Swiss army knives. Two, as recent history shows, instrumentalist educational systems tend to exclude or derogate the humanistic disciplines, such as history and philosophy, which are the natural and nourishing home of the projects of edifying self-education that are required if one is to aspire to and attain good ethical and intellectual conduct. The project of perfecting one's intellectual conduct does not flourish within an educative and social environment dominated by rote learning of practicable skills dictated by concerns 


\section{8}

\section{Ian James Kidd}

about economic productivity. Three, the instrumentalist privileging of economic and "practical" needs inevitably conflicts with the demands of intellectual humility. For instance, there are, prima facie, good economic reasons to ignore the reasonable confidence of scientists who warn of the environmental costs of carbon-intensive economic activities and of the mechanized form of the global food system. Four, instrumentalist education erodes the ideal of teachers as exemplars of virtue, since what a student expects is an efficient transmitter of knowledge, and that does not, in itself, require them to be exemplars of good intellectual conduct, much less the beautiful, "saint-like" sage described in the ancient virtue traditions.

Alongside the performative and instrumentalist conceptions, there are two further factors that are hostile to the cultivation and exercise of humility. The third feature of education hostile to humility is the contemporary zeal for the cultivation and protection of "passion" on the part of students concerning their beliefs and convictions. A cult of passion encourages an attitude of unfortified passionate confidence that amplifies a student's agential confidence while also nullifying their possibility of robust critical appraisal by either their peers or their teachers. In practice, this disables both the recognition-disposition and the regulation-disposition, in several ways. To start, it separates what Harry Frankfurt (2005, p. 65) calls an ideal of sincerity from an ideal of correctness, placing all emphasis upon the former to the neglect of the latter. If all that matters is the intensity of passion of one's sincere belief that $p$, rather than the issue of $p$ 's truth, then the very idea of confidence conditions to be recognized and fulfilled-and thus of humility - is lost.

The erosion of the ideal of correctness is, next, accelerated by the prevalence of relativism, constructivism, postmodernism, and other doctrines of "truth-denial," as Bernard Williams dubs them $(2002$, ch. 1). If there are no truths to be accurate about, since all "truths" are "constructions" or "mere truths," then there is no need to sweat over the recognition of confidence conditions or the regulation of intellectual conduct. Nor could it make any sense for education to instill in students a "fundamental orientation" toward intellectual goods such as truth: For no such truths exist toward which to be oriented, fundamentally or in any other way.

Truth-denial might take a more specific form and this is, finally, the "scientistic" conviction that there are truths to be recognized and respected, but only within the domain of scientific knowledge and inquiry. If so, then except concerning the deliverances of science, one can believe- "passionately" and "sincerely"-whatever one likes, for there is no question of confidence concerning beliefs and convictions in the ethical, aesthetic, and other spheres of life. The scope of confidence, and, hence, of humility, is therefore radically delimited, and the result is, in Wittgenstein's words, that students come to suppose that "scientists exist to instruct them" in the realm of truth, while "poets and musicians" can only entertain and "give them pleasure"-with the result that the very idea that humanistic scholars and disciplines might 
have truths of their own to convey "does not occur" (1980, p. 36). In such cases, humility is impaired either by the rejection of truth or by the restriction of truth to the delimited domain of science, in a way that collapses or confines the basis for the dispositions to recognize confidence conditions and regulate one's conduct accordingly.

The fourth obstacle to the cultivation and exercise of humility are the practical realities of modern education, which create sub-optimal conditions for edifying education. Obvious examples, too familiar to need specifying, include increasing class sizes, bureaucratization of educational practice and policy, top-down imperatives to be "relevant" or have "impact," and the decline, especially in higher education, of one-on-one-teaching (see, e.g., Schuster and Finkelstein, 2006, and Slaughter and Rhoades, 2004). Doubtless educators in different countries and systems will add their own specific betes noires, such as the Research Excellence Framework in the U.K. A mais objection to such developments is their negative effect on teaching-no least of how they render practically impossible the "constant Attention" and "particular Attention" that Locke judged essential to aretaic education. Such pressures and constraints preclude the formation of the rich, trusting, and sustained relationships between students and their teachers and among teachers as colleagues. They also erode the edifying, humanistic conception of education as an arena for the cultivation and exercise of the virtues that are, for Plato and for Confucius, the grounds of social and civic life.

Such transformations, at least at the academic level, have a further negative effect and it takes the form of an increasing incredulity on the part of students to the very idea of educators-lecturers, tutors-being exemplars of good intellectual conduct that they ought to emulate. My sense is that most of my students regard my aspiration to good intellectual conduct as part-and-parcel of my role as a teacher of philosophy, but the closely related idea that they might, let alone ought, embrace the project of cultivating virtuous conduct seems to them as—-to quote Williams (2006b, p. 10)—“suspect" or, worse, "priggish." The idea that education ought to edify, therefore, appears as a possible project to be considered by "student-consumers" facing a diverse menu of educational "options," rather than an essential or integral component of the pursuit of a flourishing and good life.

These four obstacles to virtue in general, and to humility in particular, are just a selection and-rather depressingly—very many more could be identified with relative ease. Certain of these obstacles are hostile to virtue in general, such as performativism, while others, such as the "cult of passion," are specifically hostile to humility. Such educational conceptions and attitudes might disable humility directly, perhaps by artificially narrowing a student's sense of the range of confidence conditions that they ought to respect, or they might disable it indirectly by creating a wider social and educational culture within which educating for virtues appears idle, indulgent, "priggish," or eccentric and, thus, excluded from the moral imagination of those individuals and of their society. 


\section{Ian James Kidd}

Interestingly, such concerns about education are often expressed using a charged rhetoric of corruption: of "the mission of humanistic scholarship" for Martha Nussbaum (2010, p. 130) or of scholars' status as "custodians" of a "complex intellectual inheritance" for Stefan Collini (2012, p. 199). These and other critics use this rhetoric of corruption to refer, at least partly, to the tendency of the educational systems they challenge to encourage and enable a variety of ethical and intellectual vices-myopia, selfishness, conformity-rather than a corresponding set of virtues. I suggest that we might describe educational systems that are conducive to the cultivation and exercise of vices as corrupting, and those conducive to virtues as edifying.

My judgment is clearly that much of modern education is corrupting, at least as concerns the virtue of intellectual humility. I therefore align myself with Nussbuam, Collini, and other contemporary critics. This does not, of course, imply that students are thereby debarred from cultivating their virtues, since education is only one place where they can do that. But, of course, educational institutions will often be one of the best places for students to learn to cultivate and exercise their virtues. If so, the corruption of such edifying spaces by performativism and related conceptions is a source of serious concern-especially if, as Martin Heidegger once warned, the deep tendencies that are corrupting education are also busily corrupting many other areas of human life (see Cooper, 2002).

If these concerns are correct, then contemporary educational systems are failing in what many writers since antiquity identified as one of its primary purposes: to induct, inspire, and instruct students in the self-educative project of cultivating and exercising the virtues that are integral to a good and flourishing life. Indeed, the fact that calls for such edifying education are as historically familiar as complaints about the corrupting reality brings with it an ironic and depressing sense of humility - this time, of how much there is to be done and of doubt about whether we can aspire to the confidence to do it. ${ }^{1}$

\section{NOTE}

1 I offer my thanks to Kristoffer Ahlstrom-Vij, Jason Baehr, David E. Cooper, Rune Nyrup, Bob Roberts, Sarah Connell, and an anonymous referee for their comments and encouragement. This paper was written during an Addison Wheeler Fellowship. 